\title{
Natural History of Isolated Below-Knee Vein Thrombosis in Patients with Spinal Cord Injury
}

\author{
Jang-Hyuk Cho ${ }^{1}\left(\mathbb{D}\right.$ and Dong-Gyu Lee ${ }^{2, *}$ (D) \\ 1 Department of Physical Medicine, Keimyung University Dongsan Hospital, School of Medicine, \\ Keimyung University, Daegu 42601, Korea; rehacho@hanmail.net \\ 2 Department of Physical Medicine and Rehabilitation, College of Medicine, Yeungnam University, \\ Daegu 42415, Korea \\ * Correspondence: painfree@yu.ac.kr
}

Citation: Cho, J.-H.; Lee, D.-G.

Natural History of Isolated

Below-Knee Vein Thrombosis in Patients with Spinal Cord Injury. Healthcare 2021, 9, 861. https:// doi.org/10.3390/healthcare9070861

Academic Editors: Rahman Shiri and Pedram Sendi

Received: 1 June 2021

Accepted: 5 July 2021

Published: 8 July 2021

Publisher's Note: MDPI stays neutral with regard to jurisdictional claims in published maps and institutional affiliations.

Copyright: (c) 2021 by the authors. Licensee MDPI, Basel, Switzerland. This article is an open access article distributed under the terms and conditions of the Creative Commons Attribution (CC BY) license (https:// creativecommons.org/licenses/by/ $4.0 /)$.

\begin{abstract}
In the general population, serial imaging is recommended over anticoagulant therapy for below-knee deep vein thrombosis (BKDVT). However, no clinical trial in Asian patients with spinal cord injury and BKDVT has been performed. Therefore, we evaluated the natural course of BKDVT in patients with acute spinal cord injury. We retrospectively analyzed inpatients with spinal cord injury with BKDVT between 2016 and 2020. All patients underwent inpatient rehabilitation treatment and duplex ultrasonographic examination of both the lower extremities at follow-up. After screening 172 patients with acute spinal cord injury for deep vein thrombosis using duplex ultrasound, 27 patients with below-the-knee deep vein thrombosis were included in this study. The mean lower-extremity motor score (median, interquartile range) was 66.0, 54.0-74.5. Sixteen patients received a non-vitamin $\mathrm{K}$ antagonist oral anticoagulant (NOAC) for anticoagulation. None of the patients had proximal propagation according to the follow-up duplex ultrasonography. BKDVT disappearance was not significantly different between the NOAC treatment and non-treatment groups. Asian patients with spinal cord injury have a low incidence of venous thromboembolism and favorable natural history of BKDVT. We recommend serial imaging over anticoagulant therapy for BKDVT in these patients.
\end{abstract}

Keywords: spinal cord injury; deep vein thrombosis; anticoagulation; distal deep vein thrombosis; surveillance

\section{Introduction}

Patients with spinal cord injury have a high morbidity, including deep vein thrombosis [1]. Spinal cord injury is associated with high postoperative coagulability, immobility, trauma-induced venous endothelial injury, and high infection rates [2]. Pulmonary embolism is a critical and devastating event in patients with spial cord injury. Although deep vein thrombosis and pulmonary embolism are not always coincidental, deep vein thrombosis is one of the predisposing factors for pulmonary embolism [3]. Therefore, surveillance and treatment of DVT in patients with spinal cord injury is an essential strategy in preventing pulmonary embolism.

Given the high morbidity and mortality due to venous thromboembolism in spinal cord injury, thromboprophylaxis has been one of the principal treatments for patients with spinal cord injury [1]. The evidence on thromboprophylaxis for acute spinal cord injury is mostly based on studies conducted in Western patients with spinal cord injury. However, Asian populations have a relatively low risk of venous thromboembolism than their Western counterparts $[4,5]$. Asian patients with spinal cord injury have also been shown to have a relatively low risk of deep vein thrombosis [6]. The incidence of gastrointestinal bleeding has been reported to be $5-22 \%$ in patients with spinal cord injury [7]. Moreover, 5.2\% of the patients with spinal cord injury experience serious bleeding, resulting in changes in vital signs and requiring transfusions. Because of the adverse effects of thromboprophylaxis 
and low incidence of venous thromboembolism, preventive thromboprophylaxis has not been established as a standard treatment in Asian patients with acute spinal cord injury [8].

The treatment guidelines for BKDVT recommend serial imaging for 2 weeks rather than anticoagulant therapy for isolated below-knee deep vein thrombosis (BKDVT). However, if such a patient has severe symptoms or risk factors, anticoagulant therapy is recommended for BKDVT [9]. However, these guidelines are based on weak findings and low-quality evidence. Moreover, no clinical trial or retrospective study on BKDVT in patients with spinal cord injury and on the incidence of proximal propagation in BKDVT has been conducted.

Therefore, in this study, we retrospectively evaluated the significance of BKDVT in patients with spinal cord injury with or without thromboprophylaxis based on follow-up duplex ultrasonographic assessments.

\section{Materials and Methods}

\subsection{Study Participants}

Data of patients with spinal cord injury with BKDVT between 2016 and 2020 were retrospectively collected. This study was approved by the Institutional Review Board of Yeungnam University Medical Center (protocol code; 2021-04-001) and the need for written informed consent from patients was waived. This study fully conformed to the Strengthening the Reporting of Observational Studies in Epidemiology Statement. The inclusion criteria were as follows: (a) spinal cord injury, (b) BKDVT diagnosis from duplex ultrasonography, and (c) follow-up duplex ultrasonographic assessment.

Although the global guidelines for acute spinal cord injury patients recommend routine anticoagulant thromboprophylaxis to reduce venous thromboembolism [10], South Korean medical societies do not have such guidelines. Therefore, around 2018, our hospital adopted short-term follow-up duplex ultrasonographic examinations instead of anticoagulant therapy in BKDVT according to the guidelines of the American College of Chest Physicians [11]. All inpatients with spinal cord injury routinely underwent rehabilitation therapy consisting of physical therapy, functional electrical stimulation, compression stocking application, and tilt table standing training.

Therefore, our patients with spinal cord injury had not received thromboprophylaxis. Duplex ultrasonographic assessments were routinely conducted in patients with spinal cord injury with D-dimer levels $>0.5 \mu \mathrm{g} / \mathrm{mL}$ as a screening test for deep vein thrombosis. Expert physicians examined both the lower limbs using a duplex ultrasound system (LOGIQ E9; GE Healthcare, Chicago, IL, USA). BKDVT was defined as deep vein thrombosis of the leg distal to the popliteal vein [12]. Proximal propagation and disappearance of BKDVT were observed during follow-up duplex ultrasonography.

To evaluate the natural course of BKDVT in spinal cord injury, patients were divided into two groups: the non-vitamin $\mathrm{K}$ antagonist oral anticoagulant (NOAC) group and the non-NOAC treatment group. Rivaroxaban (Xarelto; Bayer AG Pharmaceuticals, Berlin, Germany), an NOAC, was prescribed as the anticoagulant.

The lower-extremity motor score was evaluated according to the guidelines of the American Spinal Injury Association [13]. The lower-extremity motor score was calculated as the sum of the manual muscle testing scores for each of the five lower-extremity muscle groups: hip flexors, knee extensors, ankle dorsiflexors, long toe extensors, and ankle plantar flexors. Manual muscle testing uses a 6-point scale from 0 to 5 . Therefore, the maximal point of the lower-extremity motor score was 50 . The lower-extremity motor score was used to analyze the relationship between immobility and BKDVT propagation. Patients with spinal cord injury were divided into walker and sitter groups. Patients who were able to independently walk indoors or outdoors were allocated to the walker group, and those who could not independently walk even with equipment were allocated to the sitter group. The effect of ambulation on deep vein thrombosis propagation was evaluated by the allocation of the patients to the two groups. 
The American Spinal Injury Association Impairment Scale is a classification scale used to classify the severity of spinal cord injury. The American Spinal Injury Association Impairment Scale is based on a 5-point scale, ranging from A (complete sensory and motor injury) to E (normal sensory and motor function) [14]. Patients with grade B have some sensory function without motor function. If motor grade of half of the key muscles below injury level is less than 3, the grade is Grade C. If at least half of the key muscles below the injury level have a muscle grade of 3 or more, then the grade is Grade D.

\subsection{Statistical Analyses}

Data input and statistical calculations were performed using SPSS ver. 25.0 (SPSS Inc., Chicago, IL, USA). Age and the lower-extremity motor score demonstrated normality in the Shapiro-Wilk test. Therefore, Student's $t$-test was used to analyze differences in these factors between the groups. The chi-square test and Fisher's exact test were applied to compare categorical factors between the non-NOAC and NOAC groups: follow-up duplex ultrasonography outcomes, ambulation, operation, and trauma. Statistical significance was set at $p<0.05$.

\section{Results}

A total of 167 patients with acute spinal cord injury were examined using duplex ultrasonography from 2016 to 2020 . In these, deep vein thrombosis was not observed in 107 patients $(64 \%)$ on duplex ultrasonograms. Sixty patients $(36 \%)$ had deep vein thrombosis within the lower extremities. Among these, 18 (11\%) and $42(25 \%)$ patients had deep vein thrombosis in the popliteal and/or thigh veins and below the knee, respectively. Of the patients with BKDVT, 15 (9\%) had not been examined using duplex ultrasonography at follow-up. These patients were treated with an anticoagulant. Finally, 27 patients with spinal cord injury (19 men and 8 women) were included in this study (Table 1$)$. The median and interquartile range of age was 64.0 years and 54.0-74.5. The median and interquartile range of lower-extremity motor score was 28.0 and 11.0-32.0. Twenty-two patients (81.5\%) could not walk, and five patients $(18.5 \%)$ could walk. Sixteen patients received anticoagulant therapy with an NOAC. Eleven patients were examined at follow-up using duplex ultrasonography without anticoagulant treatment. Initial duplex ultrasonography revealed unilateral BKDVT in 14 patients and bilateral BKDVT in 13 patients. The median and interquartile range of interval between the initial and follow-up duplex ultrasonographic examinations were 17.0 days and 10.0-23.5.

Table 1. Demographic data.

\begin{tabular}{cc}
\hline Variable & Data \\
\hline Age (Median, interquartile range) & $66.0,54.0-74.5$ \\
\hline $\begin{array}{c}\text { lower-extremity motor score } \\
\text { (Median, interquartile range) }\end{array}$ & $28.0,11.0-32.0$ \\
\hline Sex (Male: Female) & $19: 8$ \\
\hline Ambulation (No. of patients) & $22: 5$ \\
Sitter: Walker & 12 \\
Cause of injury (No. of patients) & 12 \\
Traumatic & 1 \\
Son-traumatic & 2 \\
Cord infarct & \\
Metastasis & \\
\hline
\end{tabular}


Table 1. Cont.

\begin{tabular}{cc}
\hline Variable & Data \\
\hline $\begin{array}{c}\text { Initial Duplex ultrasound (No. of patients, } \%) \\
\text { Unilateral: Bilateral }\end{array}$ & $14(51.9 \%): 13(48.1 \%)$ \\
\hline Follow-up duplex ultrasound (No. of patients) \\
Non-DVT: DVT & $11: 16$ \\
\hline Interval (day) between duplex ultrasound \\
(median, interquartile range)
\end{tabular}

DVT, deep vein thrombosis.

Table 2. Differences between anticoagulation groups.

\begin{tabular}{|c|c|c|c|}
\hline & Non-NOAC Group & NOAC Group & $p$-Value \\
\hline Number & 16 & 11 & \\
\hline \multicolumn{4}{|l|}{$\begin{array}{l}\text { The American Spinal Injury } \\
\text { Association Impairment Scale } \\
\text { (No. of patients, \%) }\end{array}$} \\
\hline A & 0 & 1 & \\
\hline $\mathrm{B}$ & 6 & 0 & \\
\hline $\mathrm{C}$ & 4 & 6 & \\
\hline $\mathrm{D}$ & 6 & 4 & \\
\hline $\begin{array}{l}\text { Age (median, interquartile } \\
\text { range) }\end{array}$ & $68,60-68$ & $63,50.5-67.5$ & 0.25 \\
\hline $\begin{array}{l}\text { Male and Female (No. of } \\
\text { patients) }\end{array}$ & $12: 4$ & $7: 4$ & 0.675 \\
\hline $\begin{array}{l}\text { lower-extremity motor score } \\
\text { (median, interquartile range) }\end{array}$ & $29.5,11.5-32.0$ & $19,8.0-32.0$ & 0.40 \\
\hline \multicolumn{4}{|l|}{ Ambulation (No. of patients) } \\
\hline Sitter vs. walker & $13: 3$ & $9: 2$ & 0.97 \\
\hline \multicolumn{4}{|l|}{$\begin{array}{l}\text { Initial duplex ultrasound (No. of } \\
\text { patients) }\end{array}$} \\
\hline Unilateral:Bilateral & $10: 6$ & $4: 7$ & 0.18 \\
\hline $\begin{array}{l}\text { Trauma vs. Non-trauma (No. of } \\
\text { patients) }\end{array}$ & $8: 8$ & $4: 7$ & 0.69 \\
\hline $\begin{array}{l}\text { Operation vs. Non-operation } \\
\text { (No. of patients) }\end{array}$ & $12: 4$ & $10: 1$ & 0.61 \\
\hline \multicolumn{4}{|l|}{$\begin{array}{l}\text { Follow-up Duplex ultrasound } \\
\text { (No. of patients) }\end{array}$} \\
\hline No DVT vs. DVT & 5:11 & $6: 5$ & \\
\hline Proximal propagation & 0 & 0 & 0.23 \\
\hline
\end{tabular}

DVT, deep vein thrombosis. 


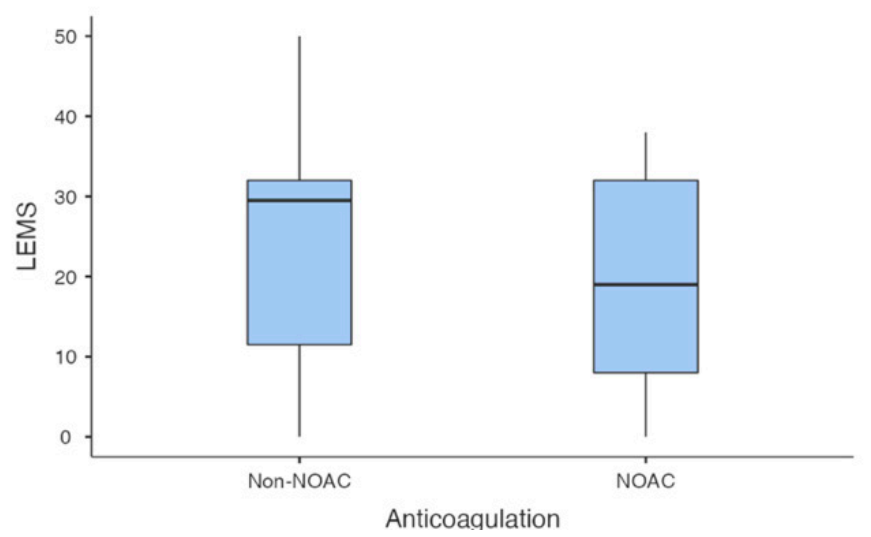

Figure 1. The lower-extremity motor score in the non-NOAC and NOAC treatment groups. There was no statistically significant difference between the two groups. NOAC, non-vitamin K antagonist oral anticoagulant.

\section{Discussion}

Irrespective of receiving anticoagulant therapy, proximal propagation of BKDVT was not observed in any of the 27 patients with spinal cord injury. Although there was no significant difference in the clinical characteristics and risk factors for deep vein thrombosis, some patients in the non-NOAC treatment group demonstrated BKDVT disappearance and no propagation at the follow-up duplex ultrasonography, which was not significantly different based on NOAC treatment.

Pulmonary embolism is a devastating event in patients with acute spinal cord injury. The incidence of deep vein thrombosis in Western patients with spinal cord injury has been reported to be $62 \%$ [15]. Even with thromboprophylaxis, the incidence of deep vein thrombosis has been reported to range from $8.5 \%$ to $21.7 \%$ in patients with acute spinal cord injury [16]. Therefore, thromboprophylaxis is recommended to reduce deep vein thrombosis and/or pulmonary embolism. However, Asian-American and Asian populations have a lower incidence of venous thromboembolism than Western populations $[4,17]$. Our results also demonstrated a low risk of deep vein thrombosis in patients with spinal cord injury. Of the acute spinal cord injury patients screened for this study, $64 \%$ did not have deep vein thrombosis on duplex ultrasound. Only $11 \%$ of the patients had deep vein thrombosis in the proximal vein, which did not present any symptoms. Therefore, it needs to be elucidated whether the benefit of thromboprophylaxis in Asian patients with spinal cord injury outweighs its risks.

The clinical impact of deep vein thrombosis is because of proximal propagation resulting in pulmonary embolism. A low incidence of proximal propagation $(5 \%)$ has been reported in inpatients with BKDVT. However, veins below the knee have a small diameter and low risk of proximal propagation [18]. In addition, BKDVT sometimes spontaneously resolves without anticoagulation treatment [19]. The clinical impact of BKDVT remains controversial because its association with pulmonary embolism has not yet been well established. Therefore, BKDVT treatment is equipoised for serial imaging and anticoagulation. However, to the best of our knowledge, there is no relevant study on the incidence of proximal propagation of BKDVT in Asian patients with spinal cord injury. Our study demonstrated that BKDVT in Asian patients with spinal cord injury has a relatively low clinical impact.

We speculated that this low risk of BKDVT propagation in patients with spinal cord injury may be attributable to race and the availability of a public health insurance system. As previously mentioned, Asians have a low risk of venous thromboembolism in the general population. The incidence of deep vein thrombosis in Korean patients with acute spinal cord injury has been reported to be $27.6 \%$ [6]. In this study, $21.1 \%$ of patients had an isolated distal deep vein thrombosis. Only $6.5 \%$ of the patients with acute spinal cord injury had a proximal deep vein thrombosis. Moreover, no fatal pulmonary embolism cases 
had occurred. The clinical impact of thromboprophylaxis in patients with acute spinal cord injury has been reported in Western populations. This result can be explained by the high incidence and mortality of pulmonary embolism in Western patients with spinal cord injury. Therefore, the clinical practice guidelines for acute spinal cord injury recommend anticoagulant thromboprophylaxis to minimize the risk of venous thromboembolism [1]. Considering the low incidence of fatal pulmonary embolism and deep vein thrombosis in Asian patients with spinal cord injury, anticoagulant thromboprophylaxis can be flexibly applied to Asian patients with spinal cord injury.

South Korea has an active rehabilitation system for patients with spinal cord injury. The public insurance system supports intensive rehabilitation and regulates the hospitalization period [20]. As a result, hospitalization duration at referral hospitals was reduced by approximately $25 \%$ compared with that reported previously. Hence, patients can receive early and well-organized inpatient rehabilitation treatments. We speculate that these factors also contribute to the favorable course of BKDVT in patients with acute spinal cord injury.

Gastrointestinal ulceration and bleeding are common comorbidities of acute spinal cord injury. The incidence of gastrointestinal bleeding has been reported to be $5.5 \%$ in acute spinal cord injury [21]. Fatal gastrointestinal bleeding has been reported in $2.5 \%$ of patients [22]. Cervical-level cord injury, trauma, infection, and high-dose steroid treatment increase the risk of gastrointestinal bleeding and major complications [23]. These are common factors in inpatients with acute spinal cord injury. Gastrointestinal complications are not only a frequent cause of rehospitalization but also a challenge in diagnosis [24,25]. Moreover, anticoagulant therapy increases the risk of gastrointestinal bleeding [26]. Therefore, thromboprophylaxis can be withheld in Asian patients with acute spinal cord injury with a high risk of gastrointestinal bleeding.

Motor weakness is generally known as the critical factor for deep vein thrombosis. Therefore, we analyzed whether there was a difference in the outcomes of BKDVT based on the NOAC treatment. The lower-extremity motor score and ambulatory function were not significantly affected by the outcomes of BKDVT. However, we were unable to conclude whether lower extremity weakness affects the prognosis of BKDVT. Although $81 \%$ of the patients were unable to walk independently, only seven patients had complete motor weakness, grade A and B of the American Spinal Injury Association Impairment Scale. Moreover, $74 \%$ of patients were able to move their lower extremities on the floor or in bed. Therefore, further study is required about the natural course of BKDVT for complete spinal cord injury patients.

This study had some limitations. First, it had a small sample size. We had initially screened 172 patients with spinal cord injury. The small sample size was partly because of the low incidence of venous thromboembolism in Asian populations. Therefore, a multicenter study is required to increase the sample size. Second, there was no evaluation for pulmonary embolism. Pulmonary embolism can occur without deep vein thrombosis [27]. We did not perform a routine computed tomography scan for pulmonary embolism screening in patients with BKDVT. Therefore, whether pulmonary embolism did not occur in patients with BKDVT could not be substantiated. However, in this study, patients with BKDVT were not diagnosed with pulmonary embolism.

\section{Conclusions}

Asian patients with spinal cord injury have a low incidence of venous thromboembolism and a favorable natural course of BKDVT. Therefore, a flexible strategy for deep vein thrombosis can be implemented in these patients. Finally, further studies are required to evaluate the usefulness of thromboprophylaxis in Asian patients with acute spinal cord injury.

Author Contributions: Conceptualization, J.-H.C. and D.-G.L.; methodology, D.-G.L.; formal analysis, D.-G.L.; investigation, D.-G.L.; data curation, J.-H.C.; writing-original draft preparation, J.-H.C.; writing-review and editing, D.-G.L.; supervision, D.-G.L. All authors have read and agreed to the published version of the manuscript. 
Funding: This research was funded by the Korea Institute of Machinery \& Materials, grant number: NK232D, with a grant for the Basic Research Program.

Institutional Review Board Statement: The study was conducted according to the guidelines of the Declaration of Helsinki, and approved by the Institutional Review Board of Yeungnam University Medical Center (protocol code; 2021-04-001, 9 April 2021).

Informed Consent Statement: Patient consent was waived due to retrospective design of this study.

Data Availability Statement: The data presented in this study are available upon request from the corresponding author.

Conflicts of Interest: The authors declare no conflict of interest. No commercial party having a direct financial interest in the results of the research supporting this article has or will confer a benefit on the authors or on any organization with which the authors are associated.

\section{References}

1. Prevention of venous thromboembolism in individuals with spinal cord injury: Clinical practice guidelines for health care providers. Top Spinal Cord. Inj. Rehabil. 2016, 22, 209-240. [CrossRef] [PubMed]

2. Miranda, A.R.; Hassouna, H.I. Mechanisms of thrombosis in spinal cord injury. Hematol. Oncol. Clin. N. Am. 2000, 14, 401-416. [CrossRef]

3. Authors/Task Force Members; Konstantinides, S.V.; Torbicki, A.; Agnelli, G.; Danchin, N.; Fitzmaurice, D.; Galiè, N.; Gibbs, J.S.R.; Huisman, M.V.; Humbert, M.; et al. 2014 ESC Guidelines on the diagnosis and management of acute pulmonary embolism: The Task Force for the Diagnosis and Management of Acute Pulmonary Embolism of the European Society of Cardiology (ESC) Endorsed by the European Respiratory Society (ERS). Eur. Heart J. 2014, 35, 3033-3080.

4. Lee, L.H.; Gallus, A.; Jindal, R.; Wang, C.; Wu, C.-C. Incidence of venous thromboembolism in Asian populations: A systematic review. Thromb. Haemost. 2017, 117, 2243-2260. [CrossRef]

5. Koh, I.J.; Kim, J.H.; Kim, M.S.; Jang, S.W.; Kim, C.; In, Y. Is routine thromboprophylaxis needed in Korean patients undergoing unicompartmental knee arthroplasty? J. Korean Med. Sci. 2016, 31, 443. [CrossRef]

6. Do, J.G.; Kim, D.H.; Sung, D.H. Incidence of deep vein thrombosis after spinal cord injury in Korean patients at acute rehabilitation unit. J. Korean Med. Sci. 2013, 28, 1382. [CrossRef]

7. Anwar, F.; Al-Khayer, A.; El-Mahrouki, H.; Purcell, M. Gastrointestinal bleeding in spinal injuries patient: Is prophylaxis essential. Alcohol 2013, 6, a607.

8. Liew, N.C.; Alemany, G.V.; Angchaisuksiri, P.; Bang, S.M.; Choi, G.; De Silva, D.A.; Hong, J.M.; Lee, L.; Li, Y.J.; Rajamoney, G.N.; et al. Asian venous thromboembolism guidelines: Updated recommendations for the prevention of venous thromboembolism. J. Int. Union Angiol. 2016, 36, 1-20.

9. Kearon, C.; Akl, E.A.; Ornelas, J.; Blaivas, A.; Jimenez, D.; Bounameaux, H.; Huisman, M.; King, C.S.; Morris, T.A.; Sood, N.; et al. Antithrombotic therapy for VTE disease: CHEST guideline and expert panel report. Chest 2016, 149, 315-352. [CrossRef]

10. Fehlings, M.G.; Tetreault, L.A.; Aarabi, B.; Anderson, P.; Arnold, P.M.; Brodke, D.S.; Burns, A.S.; Chiba, K.; Dettori, J.R.; Furlan, J.C.; et al. A Clinical Practice Guideline for the Management of Patients with Acute Spinal Cord Injury: Recommendations on the Type and Timing of Anticoagulant Thromboprophylaxis. Glob. Spine J. 2017, 7, 212S-220S. [CrossRef]

11. Guyatt, G.H.; Akl, E.A.; Crowther, M.; Schünemann, H.J.; Gutterman, D.D.; Lewis, S.Z. Introduction to the ninth edition: Antithrombotic therapy and prevention of thrombosis: American College of Chest Physicians evidence-based clinical practice guidelines. Chest 2012, 141, 48S-52S. [CrossRef]

12. Fleck, D.; Albadawi, H.; Wallace, A.; Knuttinen, G.; Naidu, S.; Oklu, R. Below-knee deep vein thrombosis (DVT): Diagnostic and treatment patterns. Cardiovasc. Diagn. Ther. 2017, 7 (Suppl. 3), S134. [CrossRef]

13. Marino, R.J.; Graves, D.E. Metric properties of the ASIA motor score: Subscales improve correlation with functional activities11No commercial party having a direct financial interest in the results of the research supporting this article has or will confer a benefit upon the author(s) or upon any organization with which the author(s) is/are associated. Arch. Phys. Med. Rehabil. 2004, 85, 1804-1810.

14. Cifu, D.X. Braddom's Physical Medicine and Rehabilitation; Elsevier Health Sciences: Philadelphia, PA, USA, 2020.

15. Geerts, W.H.; Code, K.I.; Jay, R.M.; Chen, E.; Szalai, J.P. A prospective study of venous thromboembolism after major trauma. N. Engl. J. Med. 1994, 331, 1601-1606. [CrossRef]

16. Spinal Cord Injury Thromboprophylaxis Investigators. Prevention of venous thromboembolism in the rehabilitation phase after spinal cord injury: Prophylaxis with low-dose heparin or enoxaparin. J. Trauma Acute Care Surg. 2003, 54, 1111-1115. [CrossRef]

17. Klatsky, A.L.; Armstrong, M.A.; Poggi, J. Risk of pulmonary embolism and/or deep venous thrombosis in Asian-Americans. Am. J. Cardiol. 2000, 85, 1334-1337. [CrossRef]

18. Masuda, E.M.; Kistner, R.L. The case for managing calf vein thrombi with duplex surveillance and selective anticoagulation. Disease-A-Month 2010, 10, 601-613. [CrossRef]

19. Monreal, M.; Ruiz, J.; Olazabal, A.; Arias, A.; Roca, J. Deep venous thrombosis and the risk of pulmonary embolism: A systematic study. Chest 1992, 102, 677-681. 
20. Shin, J.C.; Kim, D.H.; Yu, S.J.; Yang, H.E.; Yoon, S.Y. Epidemiologic change of patients with spinal cord injury. Ann. Rehabil. Med. 2013, 37, 50. [CrossRef]

21. El Masri, W.; Cochrane, P.; Silver, J. Gastrointestinal bleeding in patients with acute spinal injuries. Injury 1982, 14, 162-167. [CrossRef]

22. Leramo, O.B.; Tator, C.H.; Hudson, A.R. Massive gastroduodenal hemorrhage and perforation in acute spinal cord injury. Surg. Neurol. 1982, 17, 186-190. [CrossRef]

23. Chikuda, H.; Yasunaga, H.; Takeshita, K.; Horiguchi, H.; Kawaguchi, H.; Ohe, K.; Fushimi, K.; Tanaka, S. Mortality and morbidity after high-dose methylprednisolone treatment in patients with acute cervical spinal cord injury: A propensity-matched analysis using a nationwide administrative database. Emerg. Med. J. 2014, 31, 201-206. [CrossRef]

24. Hammond, F.M.; Horn, S.D.; Smout, R.J.; Chen, D.; DeJong, G.; Scelza, W.; Jha, A.; Ballard, P.H.; Bloomgarden, J. Acute Rehospitalizations During Inpatient Rehabilitation for Spinal Cord Injury. Arch. Phys. Med. Rehabil. 2013, 94, S98-S105. [CrossRef] [PubMed]

25. Mowrey, K. The challenge of assessing and diagnosing acute abdomen in tetraplegics: A case study. J. Neurosci. Nurs. 2007, 39, 5-8. [CrossRef]

26. Johnsen, S.P.; Sørensen, H.T.; Mellemkjœr, L.; Blot, W.J.; Nielsen, G.L.; McLaughlin, J.K.; Olsen, J.H. Hospitalisation for upper gastrointestinal bleeding associated with use of oral anticoagulants. Thromb. Haemost. 2001, 86, 563-568.

27. Schwartz, T.; Hingorani, A.; Ascher, E.; Marks, N.; Shiferson, A.; Jung, D.; Jimenez, R.; Jacob, T. Pulmonary Embolism Without Deep Venous Thrombosis. Ann. Vasc. Surg. 2012, 26, 973-976. [CrossRef] 